\title{
White-Collar Play: Reassessing Managerial Sports Games
}

Branden Buehler

This is a pre-copyedited version of an article accepted for publication in The Velvet Light Trap, volume 81 (2018) following peer review. The definitive publisher-authenticated version is available through the University of Texas Press.

\begin{abstract}
In recent years, sports media has become fixated with the act of management, with onceanonymous front office executives increasingly positioned as the new heroes of the sports world. Nowhere is this fixation more evident than in new media texts. Popular sports game franchises like Football Manager emphasize mundane administrative duties rather than action, while countless fantasy sports sites encourage players to carefully manage virtual rosters of athletes. Although sports media's managerial turn has thus far attracted little scholarly attention, a tentative consensus has begun to emerge around a few of these managerial sports games, with several scholars of sport arguing these games reinscribe troubling inequalities and signal another worrying advance of neoliberal logic - positioning athletes as resources to be optimized and figuring the world as a neatly calculable dataset. As this article argues, though, this emerging understanding of managerial sports games is incomplete. Rather than solely viewing managerial sports games as pernicious incubators of late capitalist logic, we might also consider how these games can precipitate pleasure and critique. As this article suggests, the affordances of managerial sports games uniquely complicate the divisions between work and play. As such, these games invite users to reflect on their relationship to their labor - a process that may allow users to gain a unique sense of empowerment and, moreover, to potentially scrutinize the conditions in which they work.
\end{abstract}




\section{White-Collar Play: Reassessing Managerial Sports Games}

In 2005, the writer Neal Pollack took to $\underline{\text { Slate }}$ to argue that sports fans are increasingly living in "the age of the general manager," with the once-anonymous front office executives tasked with assembling sports teams having surprisingly risen to the forefront of the sports universe - occasionally even surpassing superstar athletes in prominence. ${ }^{1}$ As Pollack wrote, "If you don't care about buying, selling, and trading, the sports world has much less to offer you these days." ${ }^{2}$ In the years since, Pollack's argument has been increasingly borne out across the sports media landscape, with film, radio, and television each showing a sustained interest in the managerial side of sports.

Perhaps most visibly, in 2011, the film Moneyball became something of an unexpected

hit. ${ }^{3}$ Its financial success was not only a surprise because sports movies have recently failed to do well at the box office, but also because of the exact sports subjects the film was dealing with, including statistics, roster assemblage, and payroll management. Indeed, to the casual movie fan, it may have come as a bit of a shock to find Brad Pitt playing a savvy general manager rather than an aging athlete seeking one last shot at glory. Other Hollywood films followed in Moneyball's wake, spotlighting managerial work instead of athletic feats. In 2014, Kevin Costner also played a general manager, anchoring Draft Day as the leader of the Cleveland Browns front office. That same year, Jon Hamm starred in Million Dollar Arm - again, not as a player or a coach, but rather as a smooth-talking agent. As critic Willie Osterweil summarized, “There's a new breed of sports movie in town." He continued, "These films celebrate the real heroes of sports, the real heroes of any workplace: the bosses."4

Looking to another segment of the sports media landscape, it can also be observed that sports radio and sports podcasts are turning their interest to off-field maneuverings. Examining 
the rankings of the most popular sports podcasts, one can find numerous podcasts devoted to fantasy sports. As the NFL and NBA drafts approach every year, draft-focused podcasts also soar up the rankings. Moreover, on several of the top-ranking podcasts, such as ESPN's “The Lowe Post" and Yahoo's "The Vertical Podcast with Woj," front office executives are regular guests. Print and web journalism, too, has become preoccupied with the work of the front office. Minor transactional events that were once relegated to the back of the sports section, like the NFL and NBA drafts, now generate copious coverage. This trend is particularly notable on the web. The NBA's free agency period, for instance, is now the source for countless stories on websites like CBS Sports, ESPN.com, The Ringer and Yahoo Sports.

Sports television - long a financial and cultural behemoth - has also moved towards management. The performance of GMs, for example, has become a common point of discussion during sports television talk shows and, as in podcasts, front office executives have become frequent guests on these programs. Furthermore, former executives are now commonly positioned as "experts" throughout sports television programming. ESPN, for example, regularly features figures such as Tom Penn, formerly an Assistant General Manager for the Portland Trail Blazers and Memphis Grizzlies; Louis Riddick, formerly the Director of Pro Personnel for the Washington Redskins and Philadelphia Eagles; and Bill Polian, formerly the General Manager for the Buffalo Bills, Carolina Panthers and Indianapolis Colts. Sports television has also become increasingly preoccupied with transactions and player evaluations. Most noticeably, this means ever-expanding coverage of events like scouting combines, drafts, free agency periods, and trade deadlines, as well as a growing place for statistics.

Perhaps no realm of the sports media landscape, however, has shown clearer evidence of a managerial fixation than the world of sports games. It might be observed, for instance, that one 
of the most routinely popular game franchises across the world is Football Manager, which places its players in charge of a soccer team, and in the process, eschews action and instead tasks players with duties ranging from scouting to roster management to payroll accounting. Indeed, the main user interface of Football Manager is meant to recall the Microsoft Office suite. Other massively popular franchises, including FIFA, Madden and NBA $2 \mathrm{~K}$, also now include managerial modes that emphasize administrative work. Madden, for example, has included an owner mode that asks players to consider issues like finances and marketing. In fact, the game mode has even asked players to set the price of team merchandise like hats and sweatshirts. Just as significant as the introduction of managerial modes to sports videogames has been the everincreasing popularity of fantasy sports, which place participants in control of virtual rosters of athletes. According to Fantasy Sports Trade Association data compiled by STATS, an estimated 56.8 million people now play fantasy sports in the USA and Canada - up from 12.6 million in $2005 .^{5}$

The increasing fascination with sports management is, in many ways, a curiosity. Traditionally, the appeal of sports has been linked to concepts like athletic excellence. However, the front office executives now ubiquitous on television networks like ESPN and valorized in movies like Draft Day operate far from the playing field. They are, in essence, white collar workers - performing tasks not too dissimilar from those routinely performed by scores of professionals working in less glamorous fields. Despite being so apparently unusual, though, the growing fixation with sports executives and their duties has largely been unexplored by sports media scholarship. That said, a few scholars of sport have begun addressing sports games' interest in managerial responsibilities. In their work, an initial take on managerial sports media texts emerges. As will be detailed below, these scholars have posited that managerial sports 
games are deeply imbricated in issues of power, as exemplified by quantitative player rating systems that position athletes as arrays of numbers. This, the scholars suggest, is a rather worrisome development, reinscribing troubling inequalities and signaling yet another advance of neoliberalism, with athletes figured as interchangeable resources to be optimized in a marketplace environment. However, these managerial sports games are ripe for further consideration - further consideration that may also shed further light on the rise of managerial texts across the sports media landscape. Rather than monolithically viewing managerial sports games as pernicious incubators of late capitalist logic, we might also consider how these games can precipitate pleasure and critique. As this article argues, the affordances of managerial sports games uniquely complicate the divisions between work and play. As such, these games invite users to reflect on their relationship to their labor - a process that may allow users to gain a unique sense of empowerment and, moreover, to potentially scrutinize the conditions in which they work.

\section{Background}

As mentioned above, a tentative consensus has begun to emerge around managerial sports games, with several scholars casting a largely skeptical eye toward the ways in which these games figure athletes as resources. Before delving into this nascent scholarship, though, some additional context would be beneficial so as to more clearly define the genre and to explain its fit within the broader gaming landscape. For the purposes of this article, managerial sports games will be defined as digital games that ask players to construct virtual rosters of athletes - a definition that includes a wide variety of texts ranging from Football Manager, a PC and mobile game whose gameplay is solely concerned with closely replicating the many details associated 
with managing a soccer squad, to popular multiplatform videogame franchises like Madden and FIFA, which include managerial gameplay modes amongst a suite of other gameplay options, to fantasy football websites and applications, most of which lack the intricacies of more complex games like Madden yet feature similar gameplay features, like the ability to acquire and trade virtual athletes.

Although managerial sports games have had particular success in recent years, as exemplified by the soaring popularity of fantasy sports, their rise has a longer trajectory. Football Manager itself has a history that stretches back to the early 1990s, as an earlier iteration of the franchise, Championship Manager, was first released in 1992. And the Championship Manager franchise was not alone in offering managerial simulation during this period. For example, the 1990s also saw the launch of the Baseball Mogul and Football Mogul game franchises - both of which placed players in the role of a combined owner/executive concerned with everything from amateur player scouting to concession pricing. Madden, meanwhile, also began offering more robust managerial features in the 1990s, introducing a "Franchise Mode" in its 1998 edition. ${ }^{6}$ It might also be noted that managerial sports games have several analog antecedents. That is to say, in the decades prior to the debut of games like Championship Manager and Baseball Mogul, sports fans had devised a number of novel ways to pit imagined teams against one another, as in "tabletop" sports simulations and earlier forms of fantasy sports that relied on statistics gathered from newspapers. That said, it was the increasing ubiquity of personal computers and the spread of the internet that helped precipitate the rise of managerial sports games on a wider scale, such that managerial gameplay is now familiar to many millions of sports fans.

To contextualize managerial sports games, too, requires looking beyond sports. Although managerial sports games are often grouped alongside other sports games, they also can easily be 
slotted into other popular game genres, such as simulation and strategy. Affinities are shared with certain sub-genres, too. Like strategic "god games," such as the Civilization series of games, managerial sports games often offer their players an omnipotent perspective beyond the scope of any one real-world figure, combining the coach, general manager and owner roles into one all-powerful front office worker with complete and total knowledge of a team's doings. And like business simulation games, such as the titles within the Rollercoaster Tycoon series, managerial sports games often allow their players to delve deeply into financial matters obsessing over contractual details and closely monitoring ever-fluctuating budgets. Even the most basic fantasy football apps can leave their players anxiously pondering how to maximize limited acquisition budgets and how to outwit their competitors in cutthroat auctions where every dollar counts. Suffice it to say, then, that managerial sports games do not stand alone in the gaming landscape - a fact that will eventually help us to better understand their features.

Given the relatively lengthy history of managerial sports games and given their close links to other popular genres that have attracted examination, one might expect managerial sports games to have been regular objects of scholarly analysis. However, this has not been the case - a situation that would appear to reflect the broader lack of scholarship addressing sports videogames. As a number of game scholars have noted, sports videogames have thus far received relatively little academic attention, particularly of the critical variety - a lack, they emphasize, that betrays both the genre's significant place in gaming history (e.g. Pong) and its continuing popularity with masses of gamers across the globe. ${ }^{7}$ To that point, the most recent versions of the dominant franchises FIFA, Madden, and NBA2K all made their way into the 2015 list of the ten best-selling games in the US. ${ }^{8}$ In the UK, meanwhile, the latest edition of the aforementioned Football Manager franchise, Football Manager 2016, made for the $2^{\text {nd }}$ best selling PC game of 
the year, while the previous year's edition, Football Manager 2015, came in right behind at number three. ${ }^{9}$ Fantasy sports, too, have received relatively scant scholarly attention of the critical variety. As Andrew Baerg notes, "the minimal scholarly attention paid to fantasy" has generally concerned itself with issues like the effects of fantasy sports on fans' media usage and fans' relations to "real sport." 10 Again, this lack of critical attention betrays the massive popularity of the subject at hand.

Although sports videogames and fantasy sports may not have received scholarly attention in line with their combined cultural ubiquity, it would also be unfair to say that they have been completely ignored by academics - particularly in recent years. While in 2006 David Leonard was able to confidently proclaim that the study of sports videogames represented "a barren wasteland of knowledge," in 2014, Baerg re-visited that claim and suggested that although the study of sports videogames continued to lag in comparison to other genres, it was also true that "scholars have slowly begun to cultivate this wasteland." ${ }^{11}$ Similarly, two years later Baerg could point to several scholars who have begun to pay critical heed to fantasy sports.

Of particular interest for this article are the occasional pieces of recent scholarship that have begun narrowing in on managerial sports games. Significantly, even though there have been but a few pieces of such scholarship, these works have been relatively uniform in their ideological readings of managerial sports games, with scholars consistently troubled by the ways these texts deliberately reduce athletes to resources. For Baerg, who has examined both sports videogames and fantasy sports in a number of pieces, this skepticism is largely rooted in the way these texts classify virtual bodies, particularly by way of quantitative classification systems. As Baerg notes, both sports videogames specifically concerned with management simulation - as in Football Manager - and those that also feature action simulation - as in FIFA and Madden - rely 
heavily on player rating systems. That is to say, all of these games translate athletes' abilities into

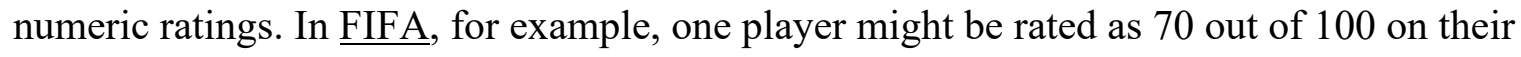
“dribbling” ability, while another might be rated as 85 out of 100. In Football Manager, meanwhile, one player might be rated as 10 out of 20 on the "bravery" category, while another might be rated as 5 out of 20 . These ratings, then, become a major part of gameplay. If, to continue the FIFA example, a virtual athlete has a poor "dribbling rating," they will be more likely to lose the ball over the course of a game.

As Baerg explains, the ability to render athletes as calculable is inevitably a matter of power. On one level, this is power exercised by game developers, as they are able to control both what constitutes an athlete and an athlete's ability, as well as how users might interact with virtual athletes. On another level, though, this is power exercised by users, as "the quantification of the athletic body through the system positions gamers to exert power through an instrumental rationality. $" 12$ In other words, numeric ratings systems transform athletes into resources to be overseen and managed by players for their own purposes. ${ }^{13}$ This transformation of athletes into resources, Baerg continues, is quite worrying, for it removes any sense that athletes are individuals with distinct thoughts and desires. In the case of FIFA, for instance, Baerg describes how players "exist in its rating system as data aggregations to be manipulated rather than as subjects with agency."14

Furthermore, Baerg argues that sports videogames' emphasis on quantification has ramifications beyond their virtual spaces, contending that these games naturalize "broader neoliberal discourses of scientifically and actuarially-inflected risk management." 15 In other words, sports videogames may encourage players to impose an artificial grid of rationality on other terrains that are similarly messy, whether that be education, policing, or any number of 
other realms of life. Similarly, he posits that the notion of control offered by fantasy sports - one that is "directly related to managing others" - "may have the effect of moving participants to perceive other decisions that need to be made through this neoliberal, risk-oriented perspective."16 Ominously, Baerg writes, "Fantasy sports participation may have much more farreaching social and cultural effects than we might imagine."17

Another scholar of sport who has cast a dubious eye towards managerial sports games has been Thomas Oates, who like Baerg, has been troubled by the way managerial sports games figure athletes as resources. As Oates writes in several works, football videogames and fantasy football sites are very much defined by their "presentation of athletes as commodities to be consumed selectively and self-consciously by sports fans." 18 The Madden franchise, for example, "offers up fantasies where the skills of a tycoon merge with control over elite athletes."19 Fantasy football sites, meanwhile, also offer up the "perspective of imagined control" over elite athletes, explicitly using the "contemporary marketplace" as the predominant metaphor for that control. ${ }^{20}$ While, as Oates admits, sports coverage has long invited sports fans to think of athletes as "property" rather than as individuals, he suggests sports games engage "this tendency with unprecedented focus, depth, and deliberateness." ${ }^{21}$ Like Baerg, then, Oates finds sports games positioning athletes as resources for fans to control - a process that necessarily erases those athletes' agency. Furthermore, because Oates is particularly interested in football games, he notes how the positioning of athletes as commodities has the worrying effect of having fans evaluate and type a labor force that is largely black. As such, managerial sports games like Madden "serve to contain Black masculinity," thus placing them alongside other managerial texts, like the NFL draft telecast, that also measure and rank black bodies. ${ }^{22}$ 
Nicholas Ware has also recently expressed skepticism regarding the ideological workings of managerial sports games, similarly focusing on the way these games treat athletes as resources. Like Oates, Ware specifically calls attention to football games. According to Ware, the Madden franchise positions players as "God-Fans" granted vast power over the game's worlds, including administrative details like contract management. Elaborating, Ware argues that in becoming "God-Fans," players end up aligned with "the capitalist concerns of the NFL" namely, team owners - and, in the process, are rewarded for being "ruthless" in assessing and valuing athletes. ${ }^{23}$ Madden, then, requires players to consider athletes as "expendable" - treating them as "interchangeable parts" to be efficiently maximized. ${ }^{24}$ Much like Baerg and Oates, Ware warns that this a troublingly dehumanizing process, as Madden players are discouraged from viewing athletes as "legitimate, living" human beings and instead asked to judge them purely by their usefulness. ${ }^{25}$

We see, then, a notable amount of consistency amongst the few scholars of sport who have begun to pay heed to managerial sports games. According to these scholars, the power relations figured by managerial sports games are highly problematic, as they naturalize a troublesome logic in which athletes are primarily figured as resources to be optimized. From this view, managerial sports games represent something of a neoliberal nightmare, sliding gamers into managerial mindsets that reify - or even exacerbate - pre-existing power imbalances while simultaneously naturalizing an erroneous view of the world as neatly rational. However, as the next section makes clear, this skepticism towards managerial sports games, while fully merited, represents an incomplete approach towards these texts. 


\section{Between Work and Play}

As the last section emphasized, scholars have thus far approached managerial sports games with a marked dubiousness. Curiously, though, little of the scholarship surrounding these games delves into what it looks like to play them. If it did, it might be hard to avoid the resemblance between managerial sports games and much of the work now required by the “information economy"/"knowledge economy"/"post-industrial economy." The sports videogames most frequently held in the popular imagination are those concerned with simulating action, which scholars have noted, strive to replicate the familar aesthetics of television sports broadcasts. ${ }^{26}$ Managerial sports games, on the other hand, largely eschew the televisual mode. For example, fantasy sports websites are, in essence, glorified tables that very much recall spreadsheet software programs like Microsoft Excel. To play, users manipulate table cells as if they were preparing a budget for an upcoming accounting project. Football Manager takes this resemblance even further. Users do not just manage spreadsheets, but also receive messages in a window meant to recall email clients like Microsoft Outlook (see Figure 1). Indeed, this is the main interface of the game. To play Football Manager is to read and respond to email.

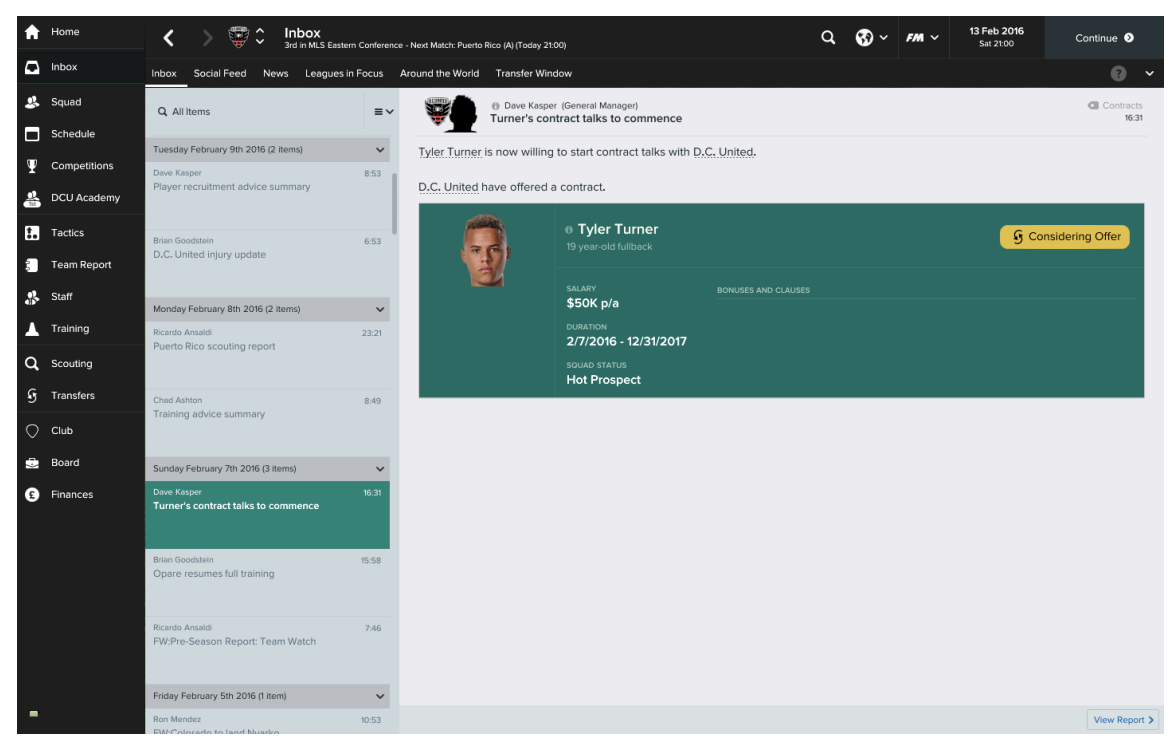

FIGURE 1. Football Manager "Inbox" interface. 
Clearly, managerial sports games stand apart from other sports games. Rather than focusing on what it is like to play a sport, these games focus on the administrative maneuvers that take place off the field, thus turning the daily drudgery of white collar work into entertainment. To fully understand them, then, means further grappling with their atypical affordances. That in mind, the following sections ask how managerial sports games' distinctive white collar interfaces shape the experience of playing these games. As will be argued, managerial sports games occupy a unique space between work and play - a unique space that allows managerial sports games to offer their players the potential for empowerment and critique in ways that few other games can. This insight, then, offers us a new way to understand managerial sports games - seeing them not just as troubling representations of late capitalism run amuck, but also as ways of navigating and making sense of this economic moment.

\section{Taking Control}

As mentioned above, the current scholarship surrounding managerial sports games has thus far glossed over the distinctive interfaces of these games. As such, this scholarship has not fully grappled with the unique experience of playing managerial sports games. That in mind, the next section details how the gameplay may serve to buffer, or even undercut, the troubling ideological premises detailed by scholars like Baerg and Oates. First, though, this section documents how the distinctive gameplay of these games may provide a meaningful sense of empowerment for many players. In this section, then, we are interested in a very basic question that, despite its simplicity, has been largely unaddressed: what makes these games appealing? What, in other words, draws players to games that are, in essence, glorified versions of productivity software? 
In answering these sorts of queries, a logical first resource would be the budding line of videogame scholarship that has questioned the stability of the work/play dichotomy and, in the process, has implicitly begun to raise similar questions. Nick Yee, for instance, has documented how the work performed in videogames, particularly MMORPGs (Massively Multiplayer Online Role-Playing Games), is "increasingly similar to actual work in business corporations."27 Players in World of Warcraft guilds, for example, can accidentally find themselves in "tedious management roles" that involve tasks like recruiting and interviewing new members, scheduling meetings, and mediating disputes. ${ }^{28}$ Looking across the gaming landscape, Yee summarizes, "Video games are blurring the boundaries between work and play very rapidly." 29 Other scholars have made similar claims about MMORPGs. Andras Lukacs, David G. Embrick and Talmadge Wright, for example, also turn their attention to World of Warcraft and conclude, "Modern virtual realms are simultaneously play and work environments: to make the distinction between the two is counterproductive." ${ }^{30}$ Scott Rettberg, meanwhile, details how World of Warcraft players to take on any number of administrative responsibilities, whether that might mean achieving sales goals or cajoling underlings to work harder. ${ }^{31} \mathrm{He}$, like Yee and Lukacs et al., summarizes, "Though playing the game is itself a form of escapism from the demands of life in the real world, it is somewhat paradoxically a kind of escapism into a second professional life, a world of work." 32

In this scholarship around MMORPGs, the notion of "escapism" emerges as something a puzzle, with Rettberg suggesting it is a "paradox" that gamers would desire to escape from daily life into "a world of work" - a mysterious incongruity which recalls the question asked above: what is it that draws players into the austere interfaces of managerial sports games? A few potential answers can be found in an article by Andrew Kuo, Richard J. Lutz and Jacob L. Hiler. 
In the work, the scholars seek to establish what exactly it means to "escape" into games, particularly in comparison to other media like film and television. Drawing on interviews with several World of Warcraft players, Kuo et al. point to escapism as a relativistic concept, commenting that "escapism is highly idiosyncratic with regards to individual differences." 33 Nonetheless, they observe several recurring patterns, with stress emerging as the most frequent motivator for "escape." Moreover, they find that stress itself is defined by a few recurring themes, perhaps most notably, coming as a result of threats against an individual's sense of agency.

Because threats against an individual's sense of agency can "lead to feelings of helplessness and frustration," Kuo et al. argue that many individuals turn to games as a way of alleviating those feelings, using games to regain a sense of control. ${ }^{34}$ That control should dominate in these interviews is perhaps not surprising - control, after all, has long been a central idea in discussions surrounding games and play, as in Mihaly Csikszentmihalyi's description of "flow" as a person being in "control of his actions and of the environment." ${ }^{\text {" N5 }}$ Nonetheless, Kuo et al.'s interviews are striking in the way they render a strong juxtaposition between gaming and non-gaming activities. For example, they interview a doctor who remarks that medical work entails countless variables and unknowable outcomes - a potentially overwhelming situation that threatens his sense of agency. Within World of Warcraft, however, there is less ambiguity and the doctor is able reaffirm his confidence in his decision-making. He summarizes, "It's about being in control versus not being in control." ${ }^{36}$ Similarly, a college student recounts how the results of tests and assignments can elude his careful preparation. That is to say, even for all of his studying, he may still do poorly on an exam. As in the case of the doctor, there is an ambiguity that threatens his sense of control. Within World of Warcraft, on the other hand, the 
scholars note that "there is an immediacy to his actions and intentions that results in positive changes and consequences." The student says of the game, "I'm definitely more in control. There's not really a time when you're not in control." Continuing, he opines, "I think it's what draws a lot of people to the game because they can do what they want in the game. ${ }^{\prime 37}$ As the scholars suggest, these types of responses are hardly surprising. Games are knowable environments where a coherent logic prevails and where players have the chance to clearly influence the world around them. Players, then, have the opportunity to reassert control and feel newly empowered.

Kuo et al.'s article suggests the existence of a strong relationship between escapism and control. What remains unclear in the wake of that insight, though, is how exactly games engender that sense of control, particularly beyond the context of Kuo et al.'s object of study, World of Warcraft. We are left to wonder, then, whether managerial sports games - their unique features included - are well-suited to empowering their players. For more insight into this question, it is worth looking to games from comparable genres. As mentioned above, managerial sports games do not just have the ability to be grouped alongside other sports games, but also alongside games in other genres, including those in the simulation and strategy genres. A particularly useful comparison would be The Sims, as it asks its players to entertain themselves with mundane tasks like job hunting and meal preparation - a scenario that parallels managerial sports games' interest in bookkeeping and inbox management._That in mind, we can turn to a piece by Sara M. Iversen in which she interviews a number of players of The Sims 2 and The $\underline{\text { Sims } 3}$, all the while looking to better understand this paradox that finds players seeking "relief from the chores of work and family" by "playing games that, to a great degree, simulate activities similar to those from which the players seek a respite." 38 


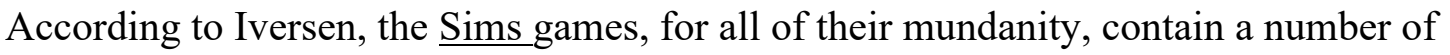
appealing "utopic" elements, of which the sensation of control is perhaps the most significant. Like Kuo et al., Iversen finds that control is central to the gameplay experience, with players contrasting the control offered by The Sims with the lack of agency in other realms of their lived experiences. As Iversen writes, the interviewees "often describe everyday life in terms of lacking control." 39 Iversen finds, though, that the games" "realistic" features serve an important function in allowing players to connect to these utopic elements. As she explains, the realistic features of The Sims ground players in the games, offering them a relatable way to enter into these game worlds. This is significant because it is only once players are situated within the world that they are able to access utopic elements like the sense of control. She argues, then, that these realistic elements "can be seen as a bridge to fantasy, dreaming of and imagining better worlds." 40

All of this scholarship in mind, we can begin to theorize why players turn to managerial sports games for an escape. Although escapism may be idiosyncratic, with every gamer looking for their own version of an "escape," it would appear that many gamers are searching for control. Moreover, if The Sims is any indication, it might be suggested that the corporate-minded interfaces of managerial sports games help ground players in the games, thus making it easier for players to achieve that sensation of control. Indeed, it is easy to imagine this exact dynamic playing out in managerial sports games. Take, for example, Football Manager. The game is sold as a fantasy wherein players get to take over the decision-making for a soccer club of their choice, whether it be a low-budget regional team like Shrewsbury Town F.C. or a multi-billiondollar team like Manchester United. The promise of control is central in this fantasy. As in World of Warcraft, Football Manager is a world where rules and expectations are clear and also where decisions are effectual. That is to say, a player can expect a defender with a high 
"dribbling" rating to dribble well and can also expect a forward with a high "heading" rating to occasionally score goals off of headers. Meanwhile, if the player wants to transfer one of these athletes, they can - their decision will play out and the game will re-shape around that choice. To go back to the example of the doctor, this is not a world in which a mystery virus baffles minds and resists treatment. Rather, it is a world where the rules and expectations are relatively obvious and, to quote the doctor, "you make a change and you see it happen."

To draw on Iversen, the game's unique affordances may help players reach these "utopic" moments of control. When a player starts a new game of Football Manager, they are quickly thrown into the Microsoft Outlook-like interface that has been mentioned above. Immediately, the player is greeted with a number of emails, dealing with everything from press conferences to staffing decisions to employment terms. While this well-known interface represents all of the drudgery of white collar work, it is also instantly recognizable. Indeed, most office workers and many others who use information technology as part of their daily lives - will instantly grasp the small details buried in the interface, like the blue dots that represent unread messages. Because this interface is instantly recognizable, it is also particularly intuitive. Managerial sports games are often information-dense. In the case of Football Manager, players can load databases giving them access to information on hundreds of thousands of athletes. The familiarity of the interface helps makes this density less daunting. The player, then, is freed to focus on assembling their winning team, and in the process, to exert control. As in the case of The Sims, then, the "realistic elements" of Football Manager can help players access the "utopic" ones.

This account begins to answer the question of how managerial sports games facilitate escapism, positing that within games like Football Manager, players have the opportunity to feel a sense of control - a sense of control that may be absent in the other parts of their lives. 
Moreover, this account begins to explains how the austere interfaces of managerial sports games can facilitate escapism - offering gamers a recognizable gateway into the games and, as such, making it easier for them, to borrow the phrasing of Kuo et al.'s student interviewee, to "do what they want in the game." ${ }^{41}$ However, this account also feels incomplete. As Gordon Calleja argues, escapism is highly contextual, with ideas of "escape" inevitably intertwining with an individual's lived experiences. ${ }^{42}$ There would seem to be added significance, then, to the way managerial sports games uniquely blur work and play.

As explained by both Kuo et al. and Iversen, individuals often turn to games for a sense of control because they feel an acute lack of agency in other parts of their lives. However, most games do not actually address that lack of agency. For example, in games like the aforementioned World of Warcraft, players have the chance to feel empowered, but in an environment largely disconnected from the other parts of their lives. Within managerial sports games, though, many players will find themselves returning to the very same environments where they work and, as such, where they may feel a lack of control. This has significant ramifications for how that in-game control may be experienced. To understand why, we can turn to a piece by Shira Chess on the subject of casual games. In the piece, Chess focuses on the Diner Dash games, which place players in the shoes of Flo, a dissatisfied white collar worker who quits her job to run a frenetic diner. Recalling the questions that have been asked throughout this section, Chess is intrigued by an apparent paradox at the heart of the Diner Dash games. On the one hand, Diner Dash's narrative emphasizes the need to escape from the drudgery of office work. On the other hand, the games figure that escape - the diner in which the player dashes - as a place defined by repetitive, menial tasks. 
According to Chess, there are risks to the way the games entangle work and play, particularly for the female gamers whom form the bulk of the games' audience. For some players, escape may be hard to find. As she writes, "Playtime could simply become work time" and in-game stresses might "re-enact stresses" that the players encounter in their work lives. ${ }^{43}$ The Diner Dash games, for example, continually call for emotional management, as gamers must work to please their fictional customers. Chess posits, then, "Just as emotional labor takes a toll on many women, so might emotional play." ${ }^{4}$ However, Chess reminds us that games are open texts that invite varying interpretations. ${ }^{45}$ As such, it would be too simple to assume all players have negative experiences with Diner Dash's interweaving of work and play. Again, the idea of control becomes significant. Chess writes:

\footnotetext{
"The Dash games offer players something that real world labor cannot: control. By giving players the opportunity to win the game, to please customers, and to see rewards for care giving, it has the potential of being satisfying in a way that might be meaningful to many women. The individual and personal experiences each player has becomes a nuanced negotiation of their own system of beliefs and helps to construct a game space that helps to retell their own personal experiences (or, perhaps, even set them right). Where the Dash games illustrate problems, they also create (at least temporary in-game) solutions."46
}

Echoing the other scholars cited above, Chess posits that control can be elusive in the course of one's daily life. In a game world, though, players can find empowerment. Chess's argument goes deeper, though. Because the Diner Dash games interweave work and play, players have the opportunity to use the game to make sense of their work lives. Players, for example, may struggle with emotional labor during a day of work - failing, perhaps, to properly stroke a manager's ego - but can see similar labor clearly rewarded within the game environment. There are potentially very real benefits, then, to the way the game interlaces work and play. As Chess 
writes, this entanglement might be draining for some players, but for others, it may help them make sense of their lived experiences.

We get a clearer sense, then, of the potential power of managerial sports games.

Managerial sports games do not offer an abstract sense of control, as in the ability to lead a band of elves into battle, but rather a sense of control grounded in the interfaces of white collar work. Thus, players can find agency in the same types of scenarios where it may otherwise desert them. Players, then, are granted the opportunity to re-negotiate their work lives, to imagine ways in which their work might potentially become more meaningful. An accounting project at work might deteriorate, but at home, a player might run numbers until their Madden franchise finds its way to a championship. Again, too, it is worth repeating just how closely managerial sports games mimic the interfaces of office work. Unlike the casual games that Chess analyzes, which figure the relationship between work and play by way of exaggerated, pixelated environments that are "safe, colorful, and full of zany characters," managerial sports games figure the relationship between work and play by way of austere tables of data. This resemblance would seem to reinforce the idea that players may turn to these games not out of longing for a different $\underline{\text { form }}$ of work, as perhaps one also does when they take on managerial responsibilities in a game like World of Warcraft, but rather a different connection to their work - a connection that involves greater clarity and agency.

This brings us back to the existent scholarship on managerial sports games. As mentioned above, the few scholars who have written on these games have been wary of the ways in which the games position athletes as resources to be optimized - a positioning that necessarily strips athletes of their humanity. In essence, this is a critique of control, with scholars worried about the way the games establish relationships of power that allow players to dominate athletes. As 
this section has been arguing, though, the control figured by managerial sports games is multifaceted. On one level, as the scholars suggest, these games reify power imbalances that exist beyond the game world. On another level, though, these games offer their players meaningful empowerment. As has been further argued, this is an empowerment that is relatively unique to the genre. Because managerial sports games make use of the very same interfaces that so many white collar workers encounter in their daily lives, they do not just offer gamers a way to relate to these games, but also offer a unique opportunity to re-imagine work - to fantasize not of orcs and elves, but of being granted control in a workplace environment. However, as the next section will explain, managerial sports games do not just offer their players ways of imagining an empowered work life, but also of critiquing the very conditions of their labor.

\section{Transcending Assumptions}

In the section above, it was suggested that managerial sports games offer the potential for meaningful empowerment - not just allowing players, as many other games do, to find control that may be absent in other parts of their lives, but also, by way of their unique interfaces, allowing players the chance to re-imagine that loss of control. As this section will argue, though, managerial sports games also offer their players the chance to critique the world around them. This is, perhaps, a counter-intuitive suggestion. As scholars like Baerg and Oates have argued, the logic of managerial sports games is highly problematic. These games, the scholars write, strip athletes of their agency, treating them like widgets whose essences can be reduced to series of numbers. And, to be sure, this is a real issue. As Ware details, games like Madden ignore many of the aspects of sporting life that might otherwise allow athletes' distinctive personalities to shine through, like the mentoring relationships that form between athletes. ${ }^{47}$ Again, though, these 
accounts do not fully incorporate the experience of playing managerial sports games. When one further interrogates the gameplay and, once again, the way that this gameplay uniquely complicates work and play, it can be observed that these games contain the seeds for criticisms of both the games themselves and, more broadly, the features of late capitalism.

To understand why we might be better served to view managerial sports games both as worrying representations of late capitalism and as potentially critical commentaries on late capitalism, it helps to turn to the work of Ted Friedman. In several pieces, Friedman examines simulation games, paying particular to the Civilization series and SimCity. A major idea within Friedman's work is that computer games should not be examined in the same fashion as other mediums. Computer gaming is distinct, he argues, in that players encounter texts repeatedly engaging games until they are mastered and, in the process, their logic fully understood. He explains, "Unlike a book of film that is engaged only once or twice, a computer game is played over and over until every subtlety is exposed, every hidden choice obvious to the savvy player."48 This distinction has significant ramifications for how we think about simulation games - managerial sports games included.

As Friedman notes, simulation games like $\underline{\text { Civilization }}$ and $\underline{\text { SimCity }}$ often come loaded with “questionable ideological premises," as in Civilization's glorification of colonization or SimCity's attempt to render the world neatly calculable (a charge, we have seen, that has also been leveled at managerial sports games). ${ }^{49}$ And, as Friedman further explains, critics have seized upon these ideological assumptions, fearing that "technology may mask the constructedness of any simulation" - an obfuscation that, in the worst case scenario, helps to instill games' problematic assumptions in their players. ${ }^{50}$ However, Friedman argues, because games are played over and over again until their logic is fully understood, they "reveal their own 
constructedness to a much greater extent than more traditional texts" - thus making their assumptions explicit. ${ }^{51}$ If one, for example, one plays SimCity with any sort of frequency, it will become quite clear that the game rewards investments in public transportation, in the process signaling an unstated premise that public transit makes a valuable contribution to the success of a city. Indeed, the player will have to identify these sorts of assumptions if they want to do well in the game. However, as Friedman writes, this is not necessarily a gateway to indoctrination. Rather, this is an opportunity for heightened understanding, for as games become demystified players are implicitly invited to question how games model the world. Friedman summarizes, "The distinct dynamics of computer gaming give the player the chance to transcend" the ideological premises of games. ${ }^{52}$

We can carry this lesson with us towards managerial sports games. Again, as the aforementioned scholars of sport have detailed, these games carry with them a number of worrying assumptions. Baerg, for example, documents how managerial sports games transform athletes into faceless data points. Oates, meanwhile, suggests that managerial sports games figure athletes as mere "commodities to be acquired, traded or discarded." ${ }^{53}$ And because Oates is particularly interested in football games, he makes the point that the marketplace metaphor often has the added effect of positioning white gamers as being in possession of black athletes. As Friedman's work reminds us, though, these troubling premises are not hidden from gamers. To return again to Football Manager, a novice player will likely begin a new game with their favorite team. If they are a big fan of that team, they might default to playing their favorite athletes and signing them to lucrative long-term deals - drawing, perhaps, on their outside knowledge of the players and, in the process, rewarding them for their loyalty to the team or for being particularly kind to fans. The game, though, will not reward this humane approach - 
players must instead learn to fit athletes into formations and contracts that align with the numerical ratings assigned by the game's designers. Similarly, many fantasy football veterans will be familiar with the first-time player who, ignoring statistics and their league's scoring system, drafts their favorite players and quickly plummets to the bottom of the standings. Again, these players must instead learn to select athletes based on quantitative data.

As Friedman argues, this process of learning a game's logic and deciding how to react to it makes a game's assumptions transparent. Inevitably, then, the ideological premises embedded in managerial sports games - that the world is calculable and that player performance can be quantified - come to the fore as gamers play them. Moreover, upon recognizing these premises, players are not necessarily led to believe this is the way the world should work. Rather, following Friedman's lead, we might suggest that players are only led to believe this is the way these specific games work. It is left to players, then, to judge how flawed this model of the world may be. While many players will undoubtedly accept these assumptions as reasonable - see, for example, the annual waves of complaints that accuse the Madden producers of botching the game's player ratings - it would also seem likely that other players will reject the assumptions, perhaps decrying them as overly simplistic or even callous.

It is worth exploring, too, whether managerial sports games invite critiques that extend beyond the ideological assumptions that have already been mentioned. Notably, several of the problematic assumptions cited by scholars like Baerg and Oates appear to be closely related to larger shifts in the sporting landscape. As many sports fans have lamented, the sports industry has undergone massive changes over the past few decades as money has flowed into both amateur and professional sports. Everywhere from soccer to basketball to football, franchise values have soared and, with them, so have television rights fees, player salaries, and ticket 
prices. This has meant, amongst many other things, an embrace of data-driven decision-making traces of which are seen in the way managerial sports games figure athletes as assets. While some of the recent changes are widely visible, as in the increasing player salaries that have accompanied inflating television rights deals, the wider effects of financialization and globalization on sporting life are relatively difficult to capture. Indeed, it is the rare corner of the sports industry that has been untouched by these recent changes. However, as Friedman might suggest, few texts are as well set-up to capture these changes as managerial sports games.

In his writings on simulation games, Friedman eventually builds to a larger point about the genre. Drawing on postmodern theorists like David Harvey and Fredric Jameson, Friedman explains that late capitalism has often eluded easy depiction. Elaborating, he states that this most recent economic stage has entailed an interconnectedness that has been difficult to adapt to traditional methods of representing the world. Economic fluxes and changes, for example, are abstractions that are hard to represent within the confines a two-dimensional map. Friedman argues, though, that simulation games are particular ideal vehicles for taking on the challenge of depicting the features of late capitalism. He claims, for instance, that games like Civilization II and SimCity consist of both "maps-in-time" and "charts-in-time" able to capture the interconnectedness of postmodern systems, "demonstrating the repercussions and interrelatedness of many different social decisions." 54 That in mind, he suggests simulation games are well-positioned to help individuals understand their place within late capitalism.

Friedman's work in mind, it is not a stretch to argue that managerial sports games are well-suited to depict how sport has evolved in the wake of financialization and globalization. In

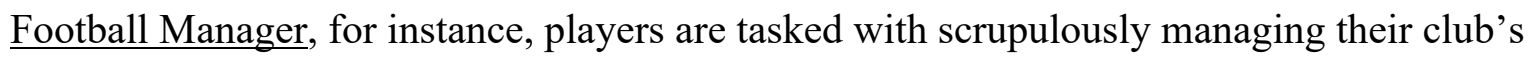
budget by way of a complex finances tab - a task that involves keeping a tight grip player wages, 
staff wages, bonuses, agent fees, facilities maintenance, transfer expenditures and other expenses while simultaneously maximizing income streams like game receipts, sponsorships, and prize money (see Figure 2). Immersed in these fluctuating tables and charts, players are exposed to some of the realities of late capitalist sport, like the need for smaller clubs to protect their best players from larger clubs able to leverage an increasing number of revenue streams. Again, these are premises that players absorb as they play the game to mastery and so, again, these are premises that become transparent. As such, players are once more invited to judge these assumptions and, once more, it is likely that some players will respond by questioning whether the effects of late capitalism have benefited sport or, rather, have skewed it for the worse.

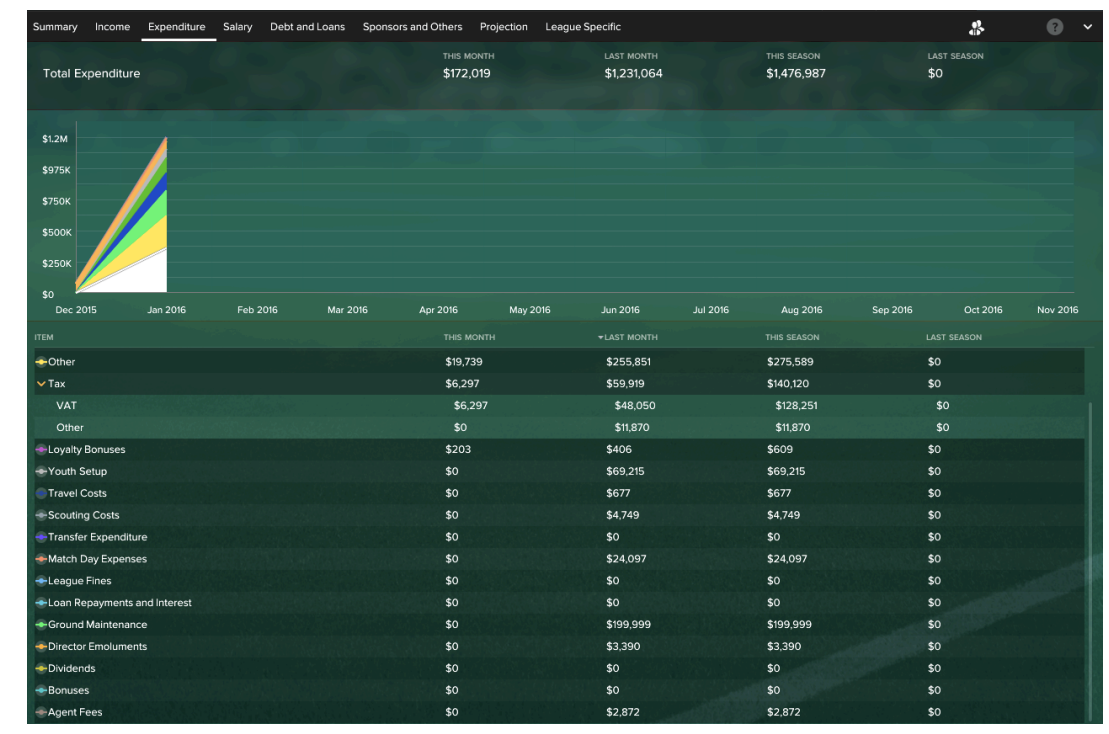

FIGURE 2. Football Manager "Expenditure" interface.

Managerial sports games, then, contain the seeds of meaningful critique both of themselves and the wider world of sports in which they are enmeshed. In playing these games, players are offered the opportunity to evaluate both how these games model the world of sport and, more broadly, how modern sport has evolved in relation to late capitalism. This in mind, we can perhaps conceive of managerial sports games in layers. On one level, they contain a set of assumptions about the modeling of athleticism - a set of assumptions thoroughly interrogated by 
scholars like Andrew Baerg and Thomas Oates. On another level, they contain a set of assumptions about the modeling of the modern sports industry, as in the way they portray the relationships between low-budget clubs and high-budget clubs. There is one more layer worth considering, though, as these games, in making use of the digital tools of office work, also contain a set of assumptions about the modeling of post-Fordist labor. As such, managerial sports games do not just invite critiques of ideological assumptions related to sport, as in the positioning of athletes as commodities and the financialization of professional sports, but also of ideological assumptions related to white collar work itself.

For one last time, we return to Football Manager. As has been mentioned throughout this article, Football Manager leans on a user interface that closely resembles the Microsoft Office suite. This choice of interface comes with a certain set of assumptions about the nature of white collar work. For example, the game presumes that white collar work is frenetic. To play Football Manager is to volunteer for an information deluge, as players are bombarded by virtual emails. A player's attention, then, is constantly pulled in many directions, for as these emails continuously arrive, they ask players to consider everything from what to say in a press conference to what to make of a new scouting report from a staff member stationed in Latin America. Perhaps not surprisingly, Football Manager forums contain occasional posts from players asking how to reduce their inbox clutter. Like many white collar workers, Football Manager players seem to be in a constant battle to reach inbox zero. The content of these virtual emails entails more assumptions about white collar work, such as the precariousness of white collar work. To that point, players receive occasional emails from their bosses on the team's board - check-ins in which the board the might clarify job performance expectations or, if things go poorly, relieve 
the player of their duties. Thus, Football Manager forums are also full of threads with titles like, "Why in the world did I get sacked?"

Again, we can suggest that as players repeatedly return to the game, these assumptions become explicit. In reference to the above examples, as players play the game, they will need to quickly learn that they are required to read their emails and that their job is anything but permanent. As such, these assumptions become open to critique. That is to say, as players come to understand the game's model of the world - in which information is dense and job security is uncertain - they will be invited to compare this model to the world around them. In so doing, they may judge both the model - and the world - unsatisfactory.

Once more, this is a situation that offers parallels to the casual game genre. In a piece that arrived not long after Chess's article on Diner Dash, Audrey Anable also analyzed the Diner Dash franchise and, in the process, explored several of the same issues as Chess, including the way the games figure the complex relationship between work and play. According to Anable, in blurring the lines between work and play, the Diner Dash games "speak to a longing for a different, less fraught, relationship to labor." Elaborating, she writes the games "create affective situations that call into question the myths and failures of the digital workplace" - stirring, for example, sensations of overwhelm and precariousness. ${ }^{55}$ While Anable is careful to point out that casual games are not necessarily "radical or even progressive media forms," she sees the potential of casual games to help players work through what it means to be in the world. ${ }^{56}$ Managerial sports games would appear to share this link. As mentioned, managerial sports games offer a version of white collar works that builds in sensations like overwhelm and precariousness. As Anable writes of Diner Dash, the foregrounding of these sensations may inevitably lead to questions regarding the very nature of white collar work, with players 
potentially casting a critical eye towards the conditions in which they labor. That in mind, managerial sports games might not just end up speaking to a longing for empowerment, but also to a desire for change. Like Anable, then, we may not necessarily look to managerial sports games as being "radical or even progressive," but nonetheless full of potential for helping players to negotiate their everyday lives.

The work of the scholars cited in the first half of this paper must be taken seriously. As they argue, managerial sports games circulate a troublesome ideology in which athletes are figured as resources to be quantified and controlled. However, without calling these texts progressive, it is also worth considering how these games offer their players a unique sense of empowerment and, moreover, how they might invite critique. As mentioned in the introduction, sports media is moving swiftly to management, with managerial sports games in the vanguard. As managerial sports text continue to have a growing place with the media landscape, there will also continue to be value in understanding both their ideological assumptions and how audiences interact with those assumptions.

\footnotetext{
${ }^{1}$ Neal Pollack, "The Cult of the General Manager," Slate, August 29, 2005, http://www.slate.com/articles/sports/sports_nut/2005/08/the_cult_of_the_general_manager.html. 
and Garry Crawford, "Is It in the Game? Reconsidering Play Spaces, Game Definitions, Theming, and Sports Videogames," Games and Culture 10, no. 6 (November 1, 2015): 571-92.

8 Jeff Grubb, “2015 NPD: The 10 Best-Selling Games of the Year," VentureBeat, January 14, 2016, http://venturebeat.com/2016/01/14/2015-npd-the-10-best-selling-games-of-the-year/.

${ }^{9}$ Christopher Dring, "How Did the UK Games Market Perform in 2015?," MCV UK, January 14, 2016, http://www.mcvuk.com/news/read/the-year-that-was-2015-in-numbers/0161201.

${ }^{10}$ Andrew Baerg, "Draft Day: Risk, Responsibility, and Fantasy Football," in Fantasy Sports and the Changing Sports Media Industry: Media, Players, and Society, ed. Nicholas David Bowman, John S. W. Spinda, and Jimmy Sanderson (Lanham: Lexington Books, 2016), 100.

${ }^{11}$ Andrew Baerg, "Sports," in The Routledge Companion to Video Game Studies, ed. Mark J. P. Wolf and Bernard Perron (Routledge, 2014), 268.

${ }^{12}$ Ibid., 144.

${ }^{13}$ Ibid.

${ }^{14}$ Ibid.

${ }^{15}$ Baerg, "Neoliberalism, Risk, and Uncertainty in the Video Game."

${ }^{16}$ Baerg, "Draft Day," 113.

${ }^{17}$ Ibid., 114.

${ }^{18}$ Thomas Oates, "New Media and the Repackaging of NFL Fandom," Sociology of Sport Journal 26, no. 1 (2009), 31.

${ }^{19}$ Ibid., 40.

${ }^{20}$ Ibid.

${ }^{21}$ Ibid., 32.

22 Ibid., 44.

${ }^{23}$ Nicholas Ware, "God-Fans of the Gridiron: Madden, Fantasy, Football, and Simulation," in Football, Culture and Power, ed. David J. Leonard, Kimberly B. George, and Wade Davis, 1 edition (London ; New York, NY:

Routledge, 2016), 97.

${ }^{24}$ Ibid., 94, 96.

25 Ibid., 94.

${ }^{26}$ See, for example, Abe Stein, "Playing the Game on Television," in Sports Videogames, ed. Mia Consalvo, Konstantin Mitgutsch, and Abe Stein (New York: Routledge, 2013), 115-137.

${ }^{27}$ Nick Yee, "The Labor of Fun: How Video Games Blur the Boundaries of Work and Play," Games and Culture 1, no. 1 (January 1, 2006), 70.

${ }^{28}$ Nick Yee, The Proteus Paradox: How Online Games and Virtual Worlds Change Us-And How They Don't (New Haven: Yale University Press, 2014), 74.

${ }^{29}$ Yee, "The Labor of Fun," 70.

${ }^{30}$ Andras Lukacs, David G. Embrick, and Talmadge Wright, "The Managed Hearthstone: Labor and Emotional Work in the Online Community of World of Warcraft," in Facets of Virtual Environments: First International Conference, FaVE 2009, Berlin, Germany, July 27-29, 2009, Revised Selected Papers, ed. Fritz Lehmann-Grube and Jan Sablatnig (Springer Science \& Business Media, 2010), 165-77, 175.

${ }^{31}$ Scott Rettberg, "Corporate Ideology in World of Warcraft," in Digital Culture, Play, and Identity: A World of Warcraft Reader, ed. Hilde Corneliussen and Jill Walker Rettberg (MIT Press, 2008), 20.

${ }^{32}$ Ibid., 26.

${ }^{33}$ Andrew Kuo, Richard J. Lutz, and Jacob L. Hiler, "Brave New World of Warcraft: A Conceptual Framework for Active Escapism," Journal of Consumer Marketing 33, no. 7 (November 9, 2016), 503.

${ }^{34}$ Ibid., 501.

35 Mihaly Csikszentmihalyi, Flow and the Foundations of Positive Psychology: The Collected Works of Mihaly Csikszentmihalyi (Springer, 2014), 142.

${ }^{36}$ Kuo et al., "Brave New World of Warcraft," 501.

37 Ibid.

38 Sara Mosberg Iversen, "Paradox and Pleasure," Mediekultur. Journal of Media and Communication Research 56 (2014), 101.

39 Ibid., 114.

40 Ibid.

${ }^{41}$ Kuo et al., "Brave New World of Warcraft," 503.

42 Gordon Calleja, "Digital Games and Escapism," Games and Culture 5, no. 4 (October 1, 2010), 349. 
${ }^{43}$ Shira Chess, "Going with the Flo," Feminist Media Studies 12, no. 1 (March 1, 2012 ), 91.

${ }^{44}$ Ibid., 96.

${ }^{45}$ Ibid., 88.

${ }^{46}$ Ibid.

47 Ware, "God-Fans of the Gridiron," 94.

48 Ted Friedman, "Civilization and Its Discontents: Simulation, Subjectivity, and Space," in On a Silver Platter: CD-ROMs and the Promises of a New Technology, ed. Greg Smith (New York University Press, 1999).

${ }^{49}$ Ibid.

${ }^{50}$ Ted Friedman, "Making Sense of Software: Computer Games and Interactive Textuality," in CyberSociety: Computer-Mediated Communication and Community, ed. Steven G. Jones (Sage Publications, 1995).

51 Ibid.

52 Friedman, "Civilization and Its Discontents."

53 Oates, Football and Manliness, 130.

${ }^{54}$ Friedman, "Making Sense of Software."

${ }^{55}$ Aubrey Anable, "Casual Games, Time Management, and the Work of Affect," Ada: A Journal of Gender, New Media, and Technology, no. 2 (June 1, 2013), n.p.

${ }^{56}$ Ibid. 


\section{References}

Anable, Aubrey. "Casual Games, Time Management, and the Work of Affect." Ada: A Journal of Gender, New Media, and Technology, no. 2 (June 1, 2013). http://adanewmedia.org/2013/06/issue2-anable/.

Baerg, Andrew. "Classifying the Digital Athletic Body: Assessing the Implications of the Player-Attribute-Rating System in Sports Video Games.” International Journal of Sport Communication, no. 4 (2011): 133-47.

—. "Draft Day: Risk, Responsibility, and Fantasy Football." In Fantasy Sports and the Changing Sports Media Industry: Media, Players, and Society, edited by Nicholas David Bowman, John S. W. Spinda, and Jimmy Sanderson, 99-120. Lanham: Lexington Books, 2016.

—. "Neoliberalism, Risk, and Uncertainty in the Video Game." In Capital at the Brink: Overcoming the Destructive Legacies of Neoliberalism, edited by Jeffrey R. Di Leo. Open Humanities Press, 2014. http://hdl.handle.net/2027/spo.12832551.0001.001.

—. "Sports." In The Routledge Companion to Video Game Studies, edited by Mark J. P. Wolf and Bernard Perron, 267-74. Routledge, 2014.

Bogost, Ian. "What Are Sports Videogames?” In Sports Videogames, edited by Mia Consalvo, Konstantin Mitgutsch, and Abe Stein, 50-66. New York: Routledge, 2013. Calleja, Gordon. "Digital Games and Escapism." Games and Culture 5, no. 4 (October 1, 2010): 335-53.

Chess, Shira. "Going with the Flo.” Feminist Media Studies 12, no. 1 (March 1, 2012): 83-99. 
Consalvo, Mia, Konstantin Mitgutsch, and Abe Stein. "Introduction: Sports Videogames. Mapping the Field.” In Sports Videogames, edited by Mia Consalvo, Konstantin Mitgutsch, and Abe Stein, 1-12. New York: Routledge, 2013.

Csikszentmihalyi, Mihaly. Flow and the Foundations of Positive Psychology: The Collected Works of Mihaly Csikszentmihalyi. Springer, 2014.

Dring, Christopher. "How Did the UK Games Market Perform in 2015?” MCV UK, January 14, 2016. http://www.mcvuk.com/news/read/the-year-that-was-2015-innumbers/0161201.

Friedman, Ted. "Civilization and Its Discontents: Simulation, Subjectivity, and Space." In On a Silver Platter: CD-ROMs and the Promises of a New Technology, edited by Greg Smith, 132-50. New York University Press, 1999.

_. "Making Sense of Software: Computer Games and Interactive Textuality." In CyberSociety: Computer-Mediated Communication and Community, edited by

Steven G. Jones, 73-89. Sage Publications, 1995.

—. "The Semiotics of SimCity." First Monday 4, no. 4 (April 5, 1999).

Grubb, Jeff. "2015 NPD: The 10 Best-Selling Games of the Year." VentureBeat, January 14, 2016. http://venturebeat.com/2016/01/14/2015-npd-the-10-best-selling-games-ofthe-year/.

"Industry Demographic Analysis with FSTA." STATS, n.d.

“Industry Demographics." FSTA: Fantasy Sports Trade Association. Accessed January 12, 2017. http://fsta.org/research/industry-demographics/.

Iversen, Sara Mosberg. "Paradox and Pleasure.” Mediekultur. Journal of Media and Communication Research 56 (2014): 100-116. 
Kuo, Andrew, Richard J. Lutz, and Jacob L. Hiler. "Brave New World of Warcraft: A Conceptual Framework for Active Escapism.” Journal of Consumer Marketing 33, no. 7 (November 9, 2016): 498-506.

Lukacs, Andras, David G. Embrick, and Talmadge Wright. “The Managed Hearthstone: Labor and Emotional Work in the Online Community of World of Warcraft." In Facets of Virtual Environments: First International Conference, FaVE 2009, Berlin, Germany, July 27-29, 2009, Revised Selected Papers, edited by Fritz Lehmann-Grube and Jan Sablatnig, 165-77. Springer Science \& Business Media, 2010.

“Moneyball (2011) - Box Office.” Box Office Mojo. Accessed May 31, 2016. http://www.boxofficemojo.com/movies/?id=moneyball.htm.

Ngai, Sianne. Our Aesthetic Categories: Zany, Cute, Interesting. Cambridge, Mass: Harvard University Press, 2012.

Oates, Thomas P. Football and Manliness: An Unauthorized Feminist Account of the NFL. Urbana: University of Illinois Press, 2017.

—. "New Media and the Repackaging of NFL Fandom." Sociology of Sport Journal 26, no. 1 (2009): 31-49.

Osterweil, Willie. "The Rise of the Sports Management Movie.” Al Jazeera America, April 27, 2014. http://america.aljazeera.com/opinions/2014/4/sportsmanagementmoviemilliondollararmmoneyball.html.

Pollack, Neal. “The Cult of the General Manager.” Slate, August 29, 2005. http://www.slate.com/articles/sports/sports_nut/2005/08/the_cult_of_the_general_ma nager.html. 
Rettberg, Scott. “Corporate Ideology in World of Warcraft." In Digital Culture, Play, and Identity: A World of Warcraft Reader, edited by Hilde Corneliussen and Jill Walker Rettberg, 19-38. MIT Press, 2008.

Stein, Abe. "Playing the Game on Television." In Sports Videogames, edited by Mia Consalvo, Konstantin Mitgutsch, and Abe Stein, 115-37. New York: Routledge, 2013.

Ware, Nicholas. "God-Fans of the Gridiron: Madden, Fantasy, Football, and Simulation." In Football, Culture and Power, edited by David J. Leonard, Kimberly B. George, and Wade Davis, 1 edition. London ; New York, NY: Routledge, 2016.

Yee, Nick. "The Labor of Fun: How Video Games Blur the Boundaries of Work and Play." Games and Culture 1, no. 1 (January 1, 2006): 68-71.

- The Proteus Paradox: How Online Games and Virtual Worlds Change Us-And How They Don't. New Haven: Yale University Press, 2014. 